\title{
Autonomic effects of selegiline: possible cardiovascular toxicity in Parkinson's disease
}

\author{
A Churchyard, C J Mathias, P Boonkongchuen, A J Lees
}

Institute of Neurology

A Churchyard

C J Mathias

P Boonkongchuen

A J Lees

University

Department of Clinical

Neurology, National

Hospital for Neurology

and Neurosurgery,

Queen Square,

London, and Imperial

College School of

Medicine at St Mary's

Hospital, London, UK

C J Mathias

Correspondence to:

Dr A Lees, National Hospital

for Neurology and

Neurosurgery, Queen

Square, London,

WC1N, UK.

Received 4 December 1996 and in revised form

14 March 1997

Accepted 25 March 1997

\begin{abstract}
Objectives-The United Kingdom Parkinson's Disease Research Group (UKPDRG) trial found an increased mortality in patients with Parkinson's disease randomised to receive selegiline (10 $\mathrm{mg} / \mathrm{day})$ and levodopa compared with those taking levodopa alone. Unwanted effects of selegiline on cardiovascular regulation have been investigated as a potential cause for the unexpected mortality finding of the UKPDRG trial.

Methods-The cardiovascular responses to a range of physiological stimuli, including standing and head up tilt, were studied in patients with Parkinson's disease receiving levodopa alone and a matched group on levodopa and selegiline.

Results-Head up tilt caused selective and often severe orthostatic hypotension in nine of 16 patients taking selegiline and levodopa, but was without effect on nine patients receiving levodopa alone. Two patients taking selegiline lost consciousness with unrecordable blood pressures and a further four had severe symptomatic hypotension. The normal protective rises in heart rate and plasma noradrenaline were impaired. The abnormal response to head up tilt was reversed by discontinuation of selegiline. Drug withdrawal caused a pronounced deterioration in motor function in 13 of the 16 patients taking selegiline.

Conclusion-Therapy with selegiline and levodopa in combination may be associated with severe orthostatic hypotension not attributable to levodopa alone. Selegiline also has pronounced symptomatic motor effects in advanced Parkinson's disease. The possibilities that these cardiovascular and motor findings might be due either to non-selective inhibition of monoamine oxidase or to amphetamine and met-amphetamine are discussed.
\end{abstract}

\section{(F Neurol Neurosurg Psychiatry 1997;63:228-234)}

Keywords: Parkinson's disease; selegiline; orthostatic hypotension

Selegiline $\mathrm{HCl}(10 \mathrm{mg} /$ day) selectively and irreversibly inhibits monoamine oxidase B (MAOB) and does not cause a "cheese effect" when taken with tyramine containing foodstuffs or levodopa. ${ }^{1}$ Blockade of MAOB inhibits metabolism of dopamine and is thought to reduce production of free radicals as well as to increase cerebral dopamine. ${ }^{2}$ Selegiline protects against MPTP induced neurotoxicity, ${ }^{2}$ and was claimed following the initial publication of the DATATOP study to slow the rate of disease progression and to delay the need for levodopa ("neuroprotective effect") in Parkinson's disease. ${ }^{3}$ However, DATATOP assumed that the anti-parkinsonian effects of selegiline were negligible. The UKPDRG ${ }^{4}$ trial and longer follow up in the DATATOP study ${ }^{56}$ failed to show a functionally significant neuroprotective effect and confirmed the symptomatic benefits of selegiline. ${ }^{78}$ Moreover, selegiline combined with levodopa was associated with greater mortality than levodopa alone in the UKPDRG trial, although no single cause was identified and no definite causal relation with selegiline was proved. ${ }^{4}$

Selegiline is metabolised to metamphetamine and amphetamine (-isomers) ${ }^{9}$ which increase synaptic release of catecholamines and deplete catecholamine stores in surviving terminals. ${ }^{10}{ }^{11}$ Amphetamine is metabolised to the false neurotransmitter $p$-hydroxyephedrine, which also depletes nerve terminals of noradrenaline. ${ }^{11}{ }^{12}$ Acute and subacute exposure of healthy humans to amphetamine results in a supine pressor response and postural hypotension ${ }^{10} 13$ and alters the pressor response to tyramine and noradrenaline, consistent with increased release of noradrenaline, depletion of noradrenaline in sympathetic terminals, and a false transmitter action of $p$-hydroxyephedrine ${ }^{11}$ Selegiline inhibits noradrenaline uptake and release in the central and peripheral nervous systems in vitro ${ }^{14}$ and is a weak indirect sympathomimetic acting on the peripheral sympathetic nerves in the rat. ${ }^{15}$ We have studied the responses to a range of cardiovascular autonomic stimuli in patients with Parkinson's disease receiving levodopa with or without selegiline to determine if autonomic dysfunction might be a relevant factor in explaining the increased mortality found in the UKPDRG study. ${ }^{4}$

\section{Patients and methods}

Consecutive patients receiving oral levodopa with or without oral selegiline $(10 \mathrm{mg} /$ day $)$ and satisfying the UKPDS Brain Bank clinical criteria for Parkinson's disease ${ }^{16}$ were entered into the study after approval by the hospital ethics committee. The presence or absence of symptomatic autonomic dysfunction did not influence entry. Patients receiving only dopamine agonists or with Hoehn and Yahr stage IV and $\mathrm{V}$ disease or age over 75 years were excluded 
because of concern that their frailty would prevent adequate performance of the tests. Those living beyond metropolitan London were excluded because of the impossibility of attending before noon. All patients taking levodopa or levodopa and selegiline in our clinic seen in a four month period were approached and all entered and completed the study. At the first examination, patients completed a detailed questionnaire of the following symptoms of autonomic dysfunction: postural and postprandial dizziness/impairment of conscious state, impotence, urinary urgency, frequency and incontinence, diminished tolerance to extremes of temperature, Raynaud's phenomenon/cold extremities, abnormal sweating, constipation, dry eyes, or dry mouth. Those not receiving selegiline were tested once. Those on selegiline were tested once on the drug and three months after its withdrawal. The severity of parkinsonism was rated at each visit (Hoehn and Yahr, North Western University Disability Scale [NWUDS], Websters).

Subjects were studied in a dedicated autonomic function laboratory before noon after taking their normal breakfast and medications. After 20 minutes supine during which patients were familiarised with the equipment and their blood pressure and heart rate had stabilised, autonomic testing using previously described techniques $^{17}$ measured blood pressure and heart rate when supine at 20 minutes and with the following manoeuvres dependent on sympathetic function: head up tilt to $45^{\circ}$ at two and 10 minutes and on standing at two minutes, the $30: 15$ ratio, the response to mental arithmetic for two minutes, application of a cold face pack for 45 seconds, and the cold pressor test for 40 seconds. Vagal function was assessed by the heart rate response to deep breathing for two minutes (R-R variation) and the Valsalva ratio (15 seconds; minimum pressure $20 \mathrm{~mm} \mathrm{Hg}$ ) examined the baroreflex, which is dependent on sympathetic and vagal function. Patients were continuously monitored with a three lead ECG. Blood pressure and heart rate were measured intermittently with a Critikon Dinamap 1846SX. The QT interval was measured manually from a 30 second ECG strip taken after 20 minutes supine so as to detect coincidental predisposition to any arrhythmias which might arise during the study. The humoral response to head up tilt, also dependent on the sympathetic system, was examined. A $16 \mathrm{G}$ venflon catheter was inserted before testing and $5 \mathrm{ml}$ blood was taken after $20 \mathrm{~min}$ utes supine and 10 minutes tilting for plasma catecholamine concentrations. Samples were immediately mixed with $0.1 \mathrm{ml}$ EGTA/reduced glutathione and stored on ice before centrifugation (3000 rpm for 10 minutes at $4^{\circ} \mathrm{C}$ ). Plasma was pipetted off, immediately frozen, and stored before measurement of noradrenaline and adrenaline concentrations with high pressure liquid chromatography (HPLC) with electrochemical detection. ${ }^{18}$ Comparison between patient groups was with Student's $t$ test and the significance of changes in each index induced by each challenge was assessed with one way analysis of variance (ANOVA) (Excel 4.0).

\section{Results}

Nine patients on levodopa (group I; three men, six women) and 16 patients taking $10 \mathrm{mg} /$ day selegiline and levodopa (group II; nine men, seven women) were matched for age (group I: 69.6 (SEM 2.3) years; group II: 68 (SEM 1.1), disease duration (group I: 7.1 (SEM 0.8) years; group II: 9.6 (SEM 0.8)), disease severity, and daily levodopa dose (table 4 ). The mean duration of selegiline treatment was 6.4 (SEM 0.8) years. Single patients in each group were taking an ergolene, amantadine, or an anticholinergic or antidepressant drug. These drugs were not changed during the duration of the study. Five group I (56\%) and seven group II (44\%) patients were participating in the UKPDRG trial. There were no differences between these and the non-trial patients with respect to disease severity or duration, age, frequency of postural dizziness, or antiparkinsonian medications. Three patients (two in group I, one in group II) had treated hypertension. No patient had symptomatic coronary artery disease or risk factors for myocardial ischaemia. All complained of constipation and a dry mouth. Five group I (56\%) and six group II (38\%) patients reported postural dizziness in the questionnaire, but this was pronounced only in four group II patients. One group II patient had frequent orthostatic hypotensive transient ischaemic attacks suggesting impairment of posterior cerebral circulation (bilateral blindness, vertigo, dysarthria, and impaired consciousness) which developed shortly after he started selegiline; multiple bilateral posterior cerebral watershed infarcts were detected on MRI, but no vertebrobasilar or carotid stenoses were identified by MR angiography. Four group I (44\%) and eight group II (50\%) patients had urinary urgency and frequency consistent with detrusor instability. None of the patients had clinical or laboratory features of multiple system atrophy or autonomic failure. ${ }^{19}$

No group I patient developed symptomatic hypotension with head up tilt (table 1, figure). By contrast, selegiline therapy was associated with severe and often symptomatic systolic hypotension on tilting (table 1 , figure). In nine (56\%) selegiline patients, systolic blood pressure fell by $20 \%$ or more after tilting for 10 minutes, whereas only two $(22 \%)$ group I patients recorded a $20 \%$ drop (figure). Head up tilt caused loss of consciousness and hypotensive seizures with an unrecordable blood pressure in two patients on selegiline (figure), only one of whom had a history of postural dizziness. The other three patients with disabling symptomatic postural dizziness before the study were very hypotensive on tilting, although with only mild symptoms. Tilting caused considerable systolic hypotension with severe dizziness and impaired consciousness or cognition in a further four patients taking selegiline, none of whom had a history of postural dizziness. Therefore, five of the six patients with severe hypotension on tilting had 
Table 1 Response of systolic and diastolic blood pressure ( $\mathrm{mm} \mathrm{Hg}$ ), heart rate (beats per minute), and plasma catecholamines (pg/ml) (mean (SEM)) to head up tilting at $45^{\circ}$ for two and 10 minutes

\begin{tabular}{|c|c|c|c|}
\hline & Group I: levodopa only $(n=9)$ & $\begin{array}{l}\text { Group II: selegiline and levodopa } \\
(n=16)\end{array}$ & Group II: selegiline ceased $(n=16)$ \\
\hline Supine systolic BP & $143.3(7.7)$ & $141.6(4.5)$ & $134.6(3.4)$ \\
\hline Tilted systolic BP at $2 \mathrm{~min}$ & $143.2(10.6)($ range 103 to 181$)$ & $123.3(5.7)^{\mathrm{a}, \mathrm{d}}($ range 73 to 136$)$ & $127.2(6.7)$ (range 79 to 183$)$ \\
\hline$\%$ Change systolic $\mathrm{BP}$ at $2 \mathrm{~min}$ & $-0.4(4.0)$ (range -13 to 28$)$ & $-12.0(3.1)^{\mathrm{b}}$ (range -42 to 0$)$ & $-5.5(4.5)^{\mathrm{e}}($ range -33.1 to 39.7$)$ \\
\hline Tilted systolic BP at $10 \mathrm{~min}$ & $138.7(10.6)$ (range 99 to 184$)$ & $116.3(9.2)^{\mathrm{a}, \mathrm{d}}($ range 0 to 175$)$ & $128.0(4.4)$ (range 92 to 164 ) \\
\hline$\%$ Change systolic $\mathrm{BP}$ at $10 \mathrm{~min}$ & $-3.9(4.0)($ range -21 to 20$)$ & $-18.8(5.9)^{\text {a }}$ (range -100 to 22$)$ & $-4.6(3.0)^{\mathrm{e}}($ range -23.1 to 23.3$)$ \\
\hline Supine diastolic BP & $87 \quad(5.4)$ & $82.9(3.1)$ & $77.6(2.0)$ \\
\hline Tilted diastolic BP at $2 \mathrm{~min}$ & $84.1(5.6)($ range 64 to 115$)$ & 77.8 (3.6) (range 52 to 103 ) & $72.1(2.6)$ (range 56 to 93 ) \\
\hline$\%$ Change diastolic $\mathrm{BP}$ at $2 \mathrm{~min}$ & $-3.4(1.8)$ (range -14 to 5$)$ & $-5.9(3.6)$ (range -30 to 29$)$ & $-6.9(2.9)$ (range -33.3 to 10.7 ) \\
\hline Tilted diastolic BP at $10 \mathrm{~min}$ & $86.6(5.9)(57$ to 115$)$ & $67.8(8.1) \quad($ range 0 to 127$)$ & $77.3(2.4)$ (range 58 to 97$)$ \\
\hline$\%$ Change diastolic $\mathrm{BP}$ at $10 \mathrm{~min}$ & $-1.0(2.8)$ (range -16 to 11 ) & $-14.5(9.6) \quad$ (range -100 to 44$)$ & $-0.3(1.8)$ (range -12.1 to 11.5 ) \\
\hline Supine HR & $75.3(3.6)$ & $79 \quad(2.5)$ & $72.2(1.9)^{\mathrm{e}}$ \\
\hline Tilted $\mathrm{HR}$ at $2 \mathrm{~min}$ & $88.9(5.4)($ range $59-100)$ & $87.3(4.8)$ (range 65 to 129$)$ & $74.8(2.0)^{\mathrm{e}}$ (range 65 to 93$)$ \\
\hline$\%$ Change $\mathrm{HR}$ at $2 \mathrm{~min}$ & $12.9(6.3)$ (range -3 to 11 ) & $11.0(5.6)$ (range -2 to 19$)$ & $3.6(1.4)$ (range -2.7 to 20 ) \\
\hline Tilted $\mathrm{HR}$ at $10 \mathrm{~min}$ & 76.9 (4.4) (range 54 to 96 ) & $81.5(3.8)$ (range 61 to 113 ) & $75.8(1.8)$ (range 63 to 92$)$ \\
\hline$\%$ Change $\mathrm{HR}$ at $10 \mathrm{~min}$ & $2.1(2.3)$ (range -10 to 13$)$ & $2.2(2.3) \quad$ (range -16 to 8$)$ & $5.2(1.5)$ (range -3.1 to 16.7$)$ \\
\hline Lying noradrenaline (NA) & $297.4(35.0)$ & $546.0(209.4)$ & $345.4(58.1)$ \\
\hline Tilted NA at $10 \mathrm{~min}$ & $402.3(55.4)$ & $514.9(106.9)$ & $413.5(62.1)$ \\
\hline Lying adrenaline & $45.1(17.0)$ & $116.6(72.1)$ & $97.0(39.6)$ \\
\hline Tilted adrenaline at $10 \mathrm{~min}$ & $71.7(23.3)$ & $118.5(52.7)$ & $91.1(19.8)$ \\
\hline
\end{tabular}

As absolute and percentage changes were similar, only the percentage changes are shown. Selegiline therapy was associated with systolic hypotension after two and more markedly at 10 minutes of head up tilting. Withdrawal of selegiline resulted in resolution of hypotension induced by tilting. Diastolic blood pressure and heart rate were unaffected. Selegiline therapy was also associated with failure of the normal rise in plasma catecholamines. Comparison between group I and group II: ${ }^{a} \mathrm{P}<0.05$; $\mathrm{P}<0.01$, two tailed $\mathrm{t}$ test. Effects of tilting within groups: $\mathrm{d}<0.01$, one way ANOVA. Comparison between group II patients before and after drug withdrawal: ${ }^{\mathrm{e}} \mathrm{P}<0.05$, paired $t$ test.

no prior orthostatic symptoms. No patient with symptomatic systolic hypotension had bradycardia suggestive of a vasovagal attack. ${ }^{20}$ All patients who became dizzy or lost consciousness were symptomatic within three minutes of tilting. No selegiline patient with symptomatic hypotension during tilting was symptomatic on standing, even in the presence of frank hypotension. Severe hypotension on tilting was not related to low supine blood pressure. Diastolic blood pressure was variably affected by tilting and standing (tables 1,2 ) and was

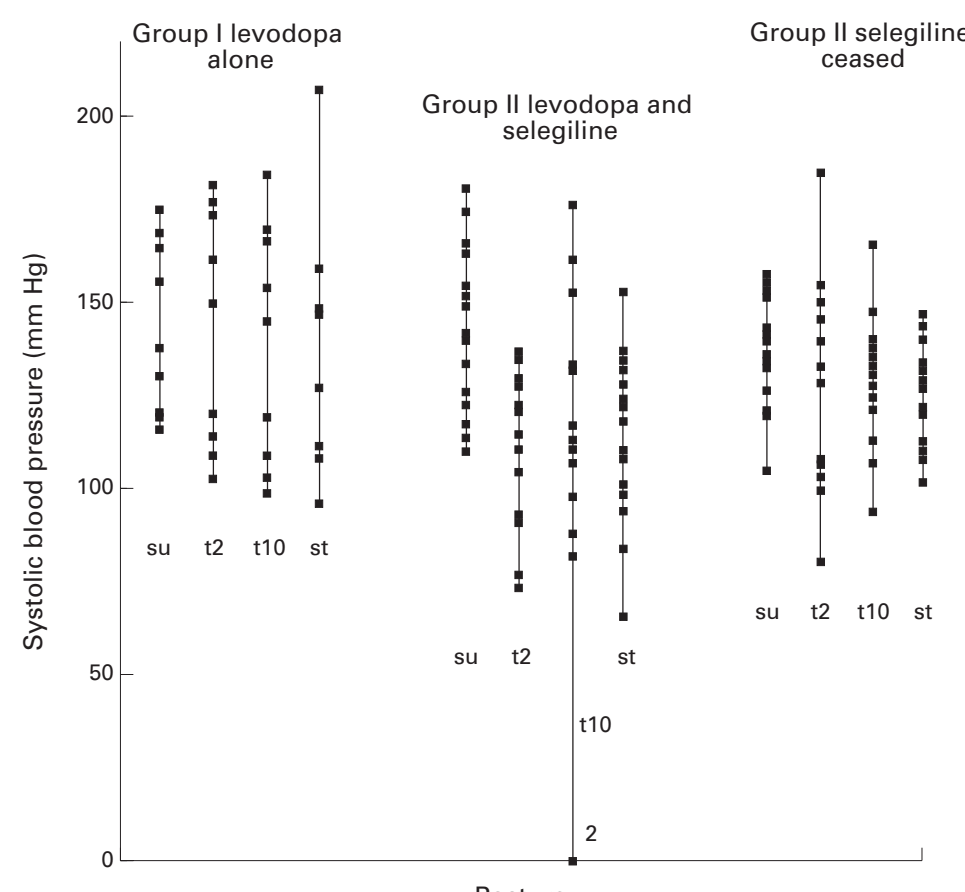

Posture

Effects of lying, head up tilt at $45^{\circ}$, and standing on systolic blood pressure (supine: su, 2 minute tilt: $t 2,10$ minute tilt: 10 , standing: st). Selegiline therapy was associated with orthostatic hypotension on tilting at 10 minutes and lesser hypotension on tilting for 2 minutes and standing. On tilting for 10 minutes, six patients on selegiline developed symptomatic hypotension and in five the blood pressure fell to below $100 \mathrm{~mm} \mathrm{Hg}$. Withdrawal of selegiline abolished symptomatic postural hypotension on tilting. The systolic blood pressure at tilting for 10 minutes fell below $100 \mathrm{~mm} \mathrm{Hg}$ in only one previously severely hypotensive patient after selegiline was stopped and this fall was asymptomatic. substantially reduced only in the presence of symptomatic systolic hypotension. Hypotension on tilting was associated with a variable and insignificant increase in heart rate and the normal rise in plasma noradrenaline, which was detected in group I, was absent (table 1). After withdrawal of selegiline, head up tilt did not result in hypotension in any patient, including those who were previously hypotensive and symptomatic, and the normal rise in plasma noradrenaline was restored (table 1 , figure).

Standing at two minutes had no effect on blood pressure or heart rate in group I patients, but caused an asymptomatic fall in systolic and diastolic blood pressures accompanied by a rise in heart rate in group II patients which was abolished by stopping selegiline (table 2). No other abnormalities of autonomic function were detected (table 3). One patient taking selegiline had 8 beats of ventricular tachycardia (VT) during deep breathing, but a subsequent 24 hour ECG and echocardiograph were normal. Selegiline therapy was not associated with an increased QT interval, even in the patient with ventricular tachycardia (group I: 0.37 (SEM 0.01) s; group II: 0.36 (SEM 0.01) $\mathrm{s}$ on selegeline, and 0.38 (SEM 0.01) s after withdrawal).

Stopping selegiline abolished the posterior circulation symptoms in the one patient with complicated orthostatic hypotension, and considerably diminished or abolished the postural symptoms in all previously affected group II patients (table 4). The mean supine systolic and diastolic blood pressures fell after selegiline withdrawal, but this was not significant. Withdrawal of selegiline caused a severe and disabling decline in motor function in 13 (82\%) patients. The daily levodopa dose (mg) was generally increased (table 4), although this was not significant, and seven (44\%) patients required pergolide and in one case apomorphine to restore comparable motor function. Within two weeks after selegiline was stopped, seven $(44 \%)$ patients developed transient 
Table 2 Response of systolic and diastolic blood pressure ( $\mathrm{mm} \mathrm{Hg}$ ) and heart rate (beats per minute) (mean (SEM)) to standing

\begin{tabular}{lcccc}
\hline & $\begin{array}{l}\text { Group I: levodopa } \\
\text { only }(n=9)\end{array}$ & $\begin{array}{l}\text { Group II: selegiline and } \\
\text { levodopa }(n=16)\end{array}$ & $\begin{array}{l}\text { Group II: selegiline } \\
\text { ceased }(n=16)\end{array}$ \\
\hline Supine systolic BP & $146.4(10.0)$ & $137.1(5.9)$ & $133.8(3.1)$ \\
$\begin{array}{l}\text { Standing systolic BP } \\
\text { \% Change systolic BP }\end{array}$ & $140.1(11.3)$ & $114.1(5.6)^{\mathrm{d}}$ & $121.5(3.5)$ \\
$\begin{array}{l}\text { Supine diastolic BP } \\
\text { Standing diastolic BP }\end{array}$ & $-3.9(2.5)$ & $-15.9(4.3)^{\mathrm{a}}$ & $-8.5(3.3)^{\mathrm{a}, \mathrm{e}}$ \\
\% Change diastolic BP & $82.1(4.1)$ & $82.8(3.4)$ & $76.3(2.2)$ \\
Supine HR & $0.9(3.1)$ & $73.5(3.5)$ & $76.7(3.7)$ \\
Standing HR & $71.8(3.3)$ & $-10.2(4.0)^{\mathrm{a}}$ & $1.5(5.9)$ \\
\% Change HR & $75.3(4.0)$ & $85.1(2.6)$ & $71.9(2.0)$ \\
30:15 ratio & $5.0(2.6)$ & $13.3(2.9)^{\mathrm{c}}$ & $74.9(3.0)^{\mathrm{e}}$ \\
\hline & $1.07(0.03)$ & $1.11(0.03)$ & $4.9(4.2)$ \\
\hline
\end{tabular}

As absolute and percentage changes were similar, only the percentage changes are shown Selegiline therapy was associated with mild asymptomatic systolic hypotension on standing which resolved after withdrawal of the drug. Comparison between group I and group II: ${ }^{\mathrm{P}} \mathrm{P}<0.05$, two tailed $t$ test. Effects of standing within groups: ${ }^{\circ} \mathrm{P}<0.05 ;{ }^{\mathrm{d}} \mathrm{P}<0.01$, one way ANOVA. Comparison between group II patients before and after drug withdrawal: ${ }^{\mathrm{e}} \mathrm{P}<0.05$, paired $t$ test.

$\mathrm{BP}=$ blood pressure; $\mathrm{HR}=$ heart rate.

Table 3 Effects of activating manoeuvres on BP and HR (mean (SEM))

\begin{tabular}{|c|c|c|c|}
\hline & $\begin{array}{l}\text { Group I: levodopa } \\
\text { only }(n=9)\end{array}$ & $\begin{array}{l}\text { Group II: selegiline } \\
\text { and levodopa }(n=16)\end{array}$ & $\begin{array}{l}\text { Group II: selegiline } \\
\text { ceased }(n=16)\end{array}$ \\
\hline Valsalva ratio & $1.13(0.03)$ & $1.15(0.03)$ & $1.07(0.02)^{\mathrm{e}}$ \\
\hline $\begin{array}{l}\mathrm{R}: \mathrm{R} \text { ratio with deep breathing } \\
\text { Mental arithmetic }\end{array}$ & $4.9(1.5)$ & $4.3(0.7)$ & $5.2(1.0)$ \\
\hline$\%$ Change in systolic BP & $5.4(2.5)$ & $2.2(5.5)$ & $1.9(3.0)$ \\
\hline$\%$ Change in diastolic BP & $(4.9)$ & $3.1(2.1)$ & $-3.0 \quad(1.8)$ \\
\hline$\%$ Change in HR & $(2.4)$ & $6.8(1.8)$ & $5.3(2.5)$ \\
\hline \multicolumn{4}{|l|}{ Response to cold face pack } \\
\hline \% Change in systolic BP & 1.8 & $-2.3(3.2)$ & $6.7 \quad(3.3)$ \\
\hline$\%$ Change in diastolic BP & $(1.9)$ & $-5.3(6.3)$ & $3.8(4.0)$ \\
\hline$\%$ Change in $\mathrm{HR}$ & $(1.2)$ & $-0.8(1.3)$ & $-2.4 \quad(1.4)$ \\
\hline \multicolumn{4}{|l|}{ Cold pressor test } \\
\hline$\%$ Change in systolic BP & $4.7 \quad(2.1)$ & $-0.5 \quad(3.3)$ & NA \\
\hline$\%$ Change in diastolic BP & $(14.0)$ & $-1.2(2.7)$ & NA \\
\hline$\%$ Change in HR & $(2.5)$ & $2.5 \quad(0.9)$ & $-3.0(1.7)^{\mathrm{f}}$ \\
\hline
\end{tabular}

As absolute and percentage changes were similar, only the percentage changes are shown. No activating procedure affected blood pressure or heart rate in either group ( $P>0.05$, paired $t$ test). Selegiline did not affect any autonomic function (comparison between groups I and II: P>0.05, two tailed $t$ test), but its withdrawal mildly reduced the Valsalva ratio and reversed the heart rate response to the cold pressor test ( ${ }^{\mathrm{e}} \mathrm{P}<0.05$; $\mathrm{f} \mathrm{P}<0.01$, paired $t$ test). However, drug withdrawal did not cause any of these indices to differ from those treated with levodopa alone $(\mathrm{P}>0.05$, paired test). $\mathrm{NA}=$ not available; $\mathrm{BP}=$ blood pressure; $\mathrm{HB}=$ heart rate.

Table 4 Effects of ceasing selegiline on clinical state and levodopa therapy (mean (SEM))

\begin{tabular}{lccc}
\hline & $\begin{array}{c}\text { Group I: levodopa } \\
\text { only }(n=9)\end{array}$ & $\begin{array}{l}\text { Group II: selegiline } \\
\text { and levodopa }(n=16)\end{array}$ & $\begin{array}{c}\text { Group II: selegiline } \\
\text { ceased }(n=16)\end{array}$ \\
\hline Postural dizziness & $5(55 \%)$ & $6 \quad(38 \%)$ & $3(19 \%)$ \\
Symptomatic motor decline & $\mathrm{NA}$ & $\mathrm{NA}$ & $13(82 \%)$ \\
Hoehn and Yahr & $2.4(0.2)$ & $2.6(0.2)$ & $3.3(0.1)^{\mathrm{b}, \mathrm{f}}$ \\
NWUDS & $45.1(0.6)$ & $43.4(0.9)$ & $39.3(1.8)^{\mathrm{b}, \mathrm{f}}$ \\
Webster & $11.7(1.6)$ & $14.7(1.1)$ & $21.2(1.4)^{\mathrm{b}, \mathrm{e}}$ \\
Daily levodopa dose (mg) & $1157(257)$ & $699.4(91.3)$ & $777.5(122.1)$ \\
\hline
\end{tabular}

Group I and II patients were matched for disease severity at the onset of the study. After withdrawal of selegiline, motor function declined despite increased daily levodopa and the addition of dopamine agonists in $7(44 \%)$. Comparison between groups I and II: ${ }^{a} \mathrm{P}<0.05$; ${ }^{\mathrm{b}} \mathrm{P}<0.01$, two tailed $t$ test. Comparison between group II and group II after withdrawal of selegiline: ${ }^{\mathrm{e}} \mathrm{P}<0.05,{ }^{\mathrm{f}} \mathrm{P}<0.01$, paired $t$ test. $\mathrm{NA}=$ not applicable.

dysphoria and one (8\%) euphoria. Cognition was improved in two (16\%) patients and hallucinations disappeared in the sole patient with this symptom.

\section{Discussion}

Sustained selegiline therapy over several years was associated with severe and selective systolic hypotension on head up tilt in nine of 16 patients. The diastolic blood pressure was affected only in the presence of severe symptomatic systolic hypotension, whereas there was little tachycardia. Withdrawal of selegiline abolished orthostatic hypotension on head up tilt. The mean supine systolic and diastolic blood pressures fell after selegiline withdrawal, but this was not significant. In a subsequent study (in preparation) we have found a similar fall in supine systolic and diastolic blood pressure which was significant and which we have tentatively interpreted as consistent with a supine pressor effect of selegiline, but the significance and cause of this finding remains uncertain. No patient had multiple system atrophy and global autonomic failure was excluded by clinical and laboratory investigation, including examination of other cardiovascular reflexes. Thus cryptic autonomic failure or drug interactions did not cause orthostatic hypotension. Volume depletion is unlikely to have contributed as all patients were examined in the morning after a normal breakfast and maintained fluid intake before testing. Severe symptomatic selegiline induced hypotension has been reported in multiple system atrophy ${ }^{21}$ and is a recognised complication of selegiline therapy in Parkinson's disease. ${ }^{7}$ Selegiline was recently reported to be associated with hypotension on head up tilt in Parkinson's disease. ${ }^{22}$

The study was open and all eligible patients on levodopa alone or levodopa and selegiline seen in our clinic over four successive months were recruited, regardless of their symptomatology; all completed the study. Thus possible selection bias in the study design was minimised. A potential criticism is that nine patients were recruited in group I versus 16 in group II. However, the two groups were well matched for age, disease severity, and disease duration, although the daily dose of levodopa and incidence of postural dizziness in group I was greater. Postural hypotension resolved after withdrawal of selegiline even though the daily dose of levodopa was generally increased and potentially hypotensive agonists were prescribed in seven patients $(44 \%)$. Thus it is unlikely that the difference in numbers reflects a selection bias towards more pronounced underlying autonomic dysfunction in patients placed on selegiline. At the time of the study, which was immediately after publication of the UKPDRG trial, ${ }^{4}$ most patients had been placed routinely on selegiline and levodopa for some years as a result of the initial DATATOP findings. ${ }^{3}$ We think that this accounts for the difference in the size of the groups.

The mechanism of the hypotensive effect of selegiline is unclear. Few patients took drugs other than levodopa, excluding a drug interaction other than with levodopa. We have subsequently found a similar hypotensive effect in a patient on selegiline monotherapy. None the less, it is not possible to determine if the hypotension found by us was due to selegiline alone or to an interaction with levodopa. Maintenance of systolic blood pressure during passive tilt is thought to be dependent on cardiac output and total peripheral vascular resistance. ${ }^{23}$ Cardiac output is dependent on heart rate, venous return, and cardiac contractility. ${ }^{24}$ Heart rate rose equally in group I and group II patients before stopping selegiline and was unaffected by head up tilt in group II patients after drug withdrawal. These results imply that cardiac contractility was impaired in those on levodopa and selegiline, assuming that total 
peripheral resistance and venous return, which were not measured, did not fall precipitously. Plasma noradrenaline was increased in response to head up tilt in group I and in group II after withdrawal of selegiline, but fell in those receiving selegiline. The rise in plasma noradrenaline in those not receiving selegiline was not significant, even though typical of the normal response for our laboratory. However, as suggested by the large SEM, there were considerable differences in concentrations between patients which may have masked a real physiological effect of head up tilt on plasma noradrenaline with such small numbers. Standing for two minutes caused a small but symptomatic fall in systolic and diastolic blood pressure accompanied by a rise in heart rate in group II patients which was abolished by stopping selegiline and which was not seen in group I (table 2). Presumably, the fall in systolic blood pressure was due to the same effects on cardiac output as occurred with tilting. Diastolic blood pressure after standing for two minutes is maintained by increased sympathetic activity ${ }^{23}$ as evidenced by the rise in heart rate. Overall, these results suggest that selegiline in combination with levodopa was associated with impaired cardiac output, whereas sympathetic function was probably also impaired as failure of heart rate and plasma noradrenaline to increase with hypotension is thought to indicate autonomic failure. ${ }^{17}$

The techniques used in this study do not discriminate between the peripheral efferent, peripheral afferent or central components of the autonomic nervous system. Dysfunction of each part of the autonomic system, all of which are affected in Parkinson's disease, ${ }^{25-29}$ may cause orthostatic hypotension. Thus, the level(s) of the autonomic system involved in systolic hypotension induced by selegiline in combination with levodopa are uncertain. Similarly, the mechanism(s) by which selegiline might induce orthostatic hypotension is unknown. Non-selective MAO inhibitors which inactivate both isoenzymes and which are not metabolised to amphetamines, cause orthostatic hypotension, ${ }^{30}{ }^{31}$ possibly because of inhibition of tyramine metabolism. ${ }^{31}$ Short term studies of selegiline at doses of $10 \mathrm{mg} /$ day found that the drug only mildly enhanced the pressor effects of tyramine, ${ }^{132}$ consistent with partial blockade of MAOA and pronounced inhibition of MAOB. Long term exposure to selegiline has been associated with progressively increasing inhibition of MAOA in rats ${ }^{33-35}$ and humans ${ }^{36}$ raising the possibility that a similar effect due to increased plasma tyramine could have resulted from chronic therapy at 10 $\mathrm{mg} /$ day. Selegiline is metabolised to metamphetamine and amphetamine. ${ }^{11}$ The psychiatric symptoms in $52 \%$ of patients after drug withdrawal and previous evidence in humans ${ }^{33}$ and rats ${ }^{33} 38-40$ suggest that selegiline exerts an amphetamine like effect in vivo. The selective hypotensive effects of selegiline on systolic blood pressure found in this study were similar to those of amphetamine and metamphetamine in human volunteers. ${ }^{10} 13$ Chronic exposure to amphetamine also results in tachyphylaxis of the pressor effects of the drug ${ }^{41}$ reduces cardiac output in dogs, ${ }^{42}$ reduces striatal dopamine and tyrosine hydroxylase in humans, ${ }^{43}$ and is neurotoxic to nigrostriatal dopaminergic terminals in experimental animals. ${ }^{44-46}$ Selegiline has been reported to be neurotoxic to cultured dopaminergic neurons. ${ }^{47}$ It is not known if these drugs are similarly toxic to sympathetic neurons in humans.

In the UKPDRG study, the mortality of those on selegiline in combination with levodopa began to increase after three years, ${ }^{4}$ whereas detailed studies of the toxicology of selegiline have been for shorter periods. ${ }^{7-9} 37$ The cause of the increased mortality in the UKPDRG study has not been identified, ${ }^{4}$ but further information will be available after completion of the cause of death examination (CODE) study. One patient in the present study with recurrent orthostatic hypotensive strokes was clearly at risk of selegiline induced mortality and another with ventricular tachicardia may have been so. If patients with orthostatic hypotension on tilting are included, $56 \%$ of the patients in this series had morbidity attributable to selegiline. Clinical studies of selegiline have shown a low incidence of symptomatic orthostatic hypotension, but did not assess changes with head up tilt and plasma concentrations of amphetamine and metamphetamine were estimated only indirectly via urinary concentrations which were comparable with those seen after oral amphetamine ingestion. ${ }^{7-9} 30$ Our finding that standing blood pressure and prior orthostatic symptoms are poor indicators of hypotension induced by head up tilt suggests that the hypotensive actions of selegiline may have previously been underestimated..$^{78}$ As amphetamines cause cardiac arrhythmias, intracranial haemorrhage and occlusive cerebral vasculitis in normal humans ${ }^{48}$ an amphetamine effect may indicate an increased risk of cardiovascular or cerebrovascular toxicity. Experience of amphetamines in parkinsonism is extremely limited, but benzedrine sulphate therapy over weeks variably affected supine blood pressure ("increased, decreased, unchanged, or vacillating") in postencephalitic parkinsonism ${ }^{49}$ and a two week course of amphetamine modestly affected supine blood pressure, but was not reported to cause postural dizziness, in Parkinson's disease. $^{50}$

The relation between our finding that selegiline in combination with levodopa has cardiovascular toxicity and the increased mortality associated with this drug regimen in the UKPDRG trial $^{4}$ is uncertain. In DATATOP,${ }^{5} 6$ which did not examine mortality as a primary endpoint or report selegiline induced mortality, patients received levodopa only when their symptoms were uncontrolled by the trial drugs. The projected median time at which DATATOP patients randomised to selegiline alone required levodopa was 2.02 years, which is substantially less than the duration of selegiline therapy in our patients (mean 6.4 years). Thus the patients in our study were not typical of those in the DATATOP trial. 
Whether or not the rare patient with Parkinson's disease on selegiline monotherapy after three years is at risk of orthostatic hypotension is unknown. Withdrawal of selegiline resulted in a severe symptomatic motor decline in $82 \%$ of patients necessitating increased dopamimetics and confirming a pronounced levodopa sparing effect. ${ }^{751}$ Thus the UKPDRG ${ }^{4}$ and DATATOP $^{5}{ }^{6}$ studies and our results are consistent with selegiline acting in Parkinson's disease only by alleviating motor symptoms.

\section{Conclusion}

We have shown that the risks of selegiline in combination with levodopa causing orthostatic hypotension in Parkinson's disease have been underestimated. Whether or not selegiline alone has similar cardiovascular toxicity is uncertain. It seems prudent to withdraw selegiline from those with symptomatic postural hypotension or concommitant cardiovascular or cerebrovascular disease. For those already on selegiline without appreciable symptomatic morbidity, but with a greater than $20 \mathrm{~mm} \mathrm{Hg}$ fall in blood pressure on standing for two minutes, gradual withdrawal with a concommitant retitration of levodopa requirements should be considered.

We thank Mrs Katherine Bleasedale-Barr (Autonomic Unit, National Hospital for Neurology and Neurosurgery) for invaluable assistance with the autonomic studies and Laura Watson able assistance with the autonomic studies and Laura Watson
(Autonomic Unit, Institute of Neurology and Neurovascular Medicine Unit, Imperial College of Medicine at St Marys Hospital, London) for measuring the plasma catecholamine pital, London) for measuring the plasma catecholamine
concentrations. AC is the beneficiary of a Kate Stillman concentrations. AC
Research Fellowship.

1 Elsworth JD, Glover V, Reynolds GP, et al. Deprenyl administration in man: a selective monoamine oxidase B inhibito without the "cheese effect". Psychopharmacol 1978;57:33-8.

2 Olanow CW. A rationale for monoamine oxidase inhibition as neuroprotective therapy for Parkinson's disease. $M o v$ Disord 1993;8(suppl):S1-7.

3 The Parkinson Study Group. The effect of tocopherol and deprenyl on the progression of disability in early Parkinson's disease. $N$ Engl F Med 1993;328:176-83.

4 Lees AJ. on behalf of the Parkinson's Disease Research Group of the UK. Comparison of therapeutic effects and Group of the UK. Comparison of therapeutic effects and
mortality data of levodopa and levodopa combined with mortality data of levodopa and levodopa combined with selegiline in patients with
$B M \mathcal{F} 1995 ; 311: 1602-7$.

5 Parkinson Study Group. Impact of deprenyl and tocopherol treatment on Parkinson's disease in DATATOP patient not requiring levodopa. Ann Neurol 1996;39:29-36.

6 Parkinson Study Group. Impact of deprenyl and tocopherol treatment on Parkinson's disease in DATATOP patient requiring levodopa. Ann Neurol 1996;39:37-45.

7 Birkmayer W, Riederer P, Ambrozi L, Youdim MBH. Implications of combined treatment with Madopar and L-deprenyl in Parkinson's disease. Lancet 1977;4:39-43.

8 Lees AJ, Kohout LJ, Shaw KM, et al. Deprenyl in Parkinson's disease. Lancet 1977;ii:791-5.

9 Reynolds GP, Elsworth JD, Blau K, et al. Deprenyl is metabolized to metamphetamine and amphetamine in metabolized to metamphetamine and

10 Gill JR, Mason DT, Bartter F. Effects of hydroxyamphetamine on the function of the sympathetic nervous system in
normotensive subjects. $\mathcal{F}$ Pharmacol Exp Ther 1967;155: normote.

11 Cavanaugh JH, Griffith JD, Oates JA. Effect of amphetamine on the pressor response to tyramine: formation of p-hydroxynorephedrine. Clin Pharmacol Ther 1970;11:65664.

12 Rangno RE, Kaufmann JS, Cavanaugh JH, et al. Effects of a false neurotransmitter, $p$-hydroxynorephedrine, on the function of adrenergic neurons in hypertensive patients. $\mathscr{f}$ Clin Invest 1973;52:952-60.

13 Martin WR, Sloan JW, Sapira JD, Jasinski DR. Physiologic, subjective and behavioural effects of amphetamine, metamphetamine, ephedrine, phenmetrazine and methylphenidate in man. Clin Pharmacol Ther 1971;12:245-60.

14 Knoll J. The possible mechanisms of action of (-)deprenyl in Parkinson's disease. F Neural Trans 1978;43:177-98.

15 Simpson LL. Evidence that deprenyl, a type B monoamine oxidase inhibitor, is an indirectly acting sympathomimetic amine. Biochem Pharmacol 1978;27:1591-5.
$16 \mathrm{Gibb}$, Lees AJ. The relevance of the Lewy body to the pathogenesis of idiopathic Parkinson's disease. 7 Neurol Neurosurg Psych 1988;51:745-52.

17 Mathias CJ, Bannister RB. Investigation of autonomic disorders. In: Bannister RB, Mathias CJ, eds. Autonomic failure. A textbook of clinical disorders of the autonomic nervous system. 3rd ed. Oxford: OUP, 1992.

18 Mathias CJ, Bannister RB, Cortelli P, et al. Clinical, autonomic and therapeutic observations in two siblings with postural hypotension and sympathetic failure due to an inability to synthesize noradrenaline from dopamine because of a deficiency of dopamine beta hydroxylase. $Q \mathcal{F}$ Med 1990;75:617-33.

19 Mathias CJ. Disorders of the autonomic nervous system. In: Bradley EG, Daroff RB, Fenichel GM, Marsden CD, eds. Neurology in clinical practice. 2nd ed. Boston: Butterworth Heinemann, 1996;2:82,1953-81.

20 Hainsworth R. Syncope and fainting. In: Bannister RB, Mathias CJ, eds. Autonomic failure. A textbook of clinical disorders of the autonomic nervous system. 3rd ed. OUP, Oxford, 1992.

21 Rae-Grant A, Young GB, Spence JD. Monoamine oxidase inhibitors and sinemet in shy-drager syndrome. Neurology 1985;35:1085-6.

22 Turkka J, Suominen K, Tolonen U, et al. Effect of selegiline on cardiovascular autonomic responses in Parkinson's disease. Acta Neurol Scand 1996;94(suppl 167):22.

23 Sprangers RLH, Wesseling KH, Imholz ALT, Imholz BPM, Wieling W. Initial blood pressure fall on stand up and exercise explained by changes in total peripheral resistance. $\mathcal{F}$ Appl Physiol 1991;70:523-30.

24 Guyton AC. In: Human physiology and mechanisms of disease. 4th ed. Philadelphia: WB Saunders, 1987

25 Ohama E, Ikuta F. Parkinson's disease: distribution of Lewy bodies and monoamine neuron system. Acta Neuropathol 1976;34:311-9.

26 Wakabayashi K, Takahashi H, Ohama E, Ikuta F. Parkinson's disease: an immunohistochemical study of Lewy body-containing neurons in the enteric nervous system. Acta Neuropathol 1990;79:581-3.

27 Gai WP, Geffen LB, Denoroy L, Blessing WW. Loss of C1 and C3 epinephrine-synthesizing neurons in the medulla and C3 epinephrine-synthesizing neurons in the medulla
oblongata in Parkinson's disease. Ann Neurol 1993;33:35767.

28 Kopp N, Denoroy L, Tommasi $\mathrm{M}$, et al. Increase in noradrenaline-synthesizing enzyme activity in medulla oblongata in Parkinson's disease. Acta Neuropathol 1982; 56:17-21.

29 Montastruc JL, Senard JM, Rascol O, Rascol A. Autonomic nervous system dysfunction and adrenoreceptor regulation in Parkinson's disease. Adv Neurol 1996;69:377-81.

$30 \mathrm{McDaniel}$ KD. Clinical pharmacology of monoamine oxidase inhibitors. Clin Neuropharmacol 1986;9:207-34.

31 Goldberg LI. Monoamine oxidase inhibitors. $7 A M A 1964$; 190:132-8.

32 Sunderland T, Mueller EA, Cohen RM, et al. Tyramine sensitivity changes during deprenyl treatment. Psychopharmacol 1985;86:432-7.

33 Gelowitz DL, Richardson JS, Wishart TB, et al. Chronic l-deprenyl or l-amphetamine: equal cognitive enhancement, unequal MAO inhibition. Pharmacol Biochem Behav 1994;47:41-5.

34 Waldmeier PC, Felner AE. Deprenil: loss of selectivity for inhibition of B-type MAO after repeated treatment. Biochem Pharmacol 1978;27:801-2.

35 Ekstedt B, Magyar K, Knoll J. Does the B form selective monoamine oxidase inhibitor lose selectivity by long term treatment? Biochem Pharmacol 1979;28:919-23.

36 Riederer $\mathrm{P}$, Youdim $\mathrm{MBH}$, Rausch WD, et al. On the mode of action of 1-deprenyl in the human nervous central system. F Neural Trans 1978;43:217-26.

37 Karoum F, Chuang LW, Eisler T, et al. Metabolism of (-) deprenyl to amphetamine and metamphetamine may be responsible for deprenyl's therapeutic benefit: a biochemical assessment. Ann Neurol 1982;32:503-9.

38 Fozard JR, Zreika M, Robin M, Palfreyman MG. The functional consequences of inhibition of monoamine oxidase type B: comparison of the pharmacological properties of l-deprenyl and MDL 72145. Naunyn Schmiedebergs Arch Pharmacol 1985;331:186-93.

39 Okuda C, Segal DS, Kuczenski R. Deprenyl alters behaviour and caudate dopamine through an amphetamine-like action. Pharmacol Biochem Behav 1992; 43:1075-80.

40 Engberg G, Elebring T, Nissbrandt H. Deprenyl (selegiline), a selective MAO-B inhibitor with active metabolites; effects on locomotor activity, dopaminergic neurotransmission and firing rate of nigral dopamine neurons. F Pharmacol Exp Ther 1991;259:841-7.

41 Rosenberg DE, Wolbach AB, Miner EJ, Isbell H. Observations on direct and cross tolerance with LSD and d-amphetamine in man. Psychopharmacol 1963;5: $1-15$.

42 Cheng HC, Long JP, Barfknecht CF, Nicholls DE. Cardiovascular effects of 2,5-dimethoxy-4-methylamphetamine. $\mathcal{F}$ Pharmacol Exp Ther 1973;186:345-54.

43 Wilson JM, Kalasinsky KS, Levey AI, et al. Striatal dopamine terminal markers in human, chronic metamphetamine users. Nat Med 1996;2:699-703.

44 Ricaurte GA, Seiden LS, Schuster CR. Further evidence that amphetamines produce long-lasting dopamine neurochemical deficits by destroying dopamine nerve fibres. Brain Res 1984;303:359-64. 
45 Preston KL, Wagner GC, Schuster CR, Seiden LS. Further evidence that amphetamines produce long-lasting dopamine neurochemical deficits by dest

46 Woolverton WL, Ricaurte GA, Forno LS, Seiden LS. Longterm effects of chronic metamphetamine administration in rhesus monkeys. Brain Res 1989;486:73-8.

47 Yu PH, Lai CT, Boulton AA. Selegiline may be toxic in presence of increased dopamine concentrations. Lancet 1996;312:703-4.
48 Brust JCM. In: Brust JCM, ed. Neurological aspects of Bubstance abuse. London: Butterworth-Heinemann, 1993 .
subst substance abuse. London: Butterworth-Heinemann, 1993.
Davis PL, Stewart WB. The use of benzedrine sulfate in postencephalitic parkinsonism. IAMA 1938;110:1890-2. 50 Parkes JD, Tarsy D, Marsden CD, et al. Amphetamines in the treatment of Parkinson's disease. $\mathcal{F}$ Neurol Neurosurg Psychiatry 1975;35:232-7.

51 Anderson KE, Girdwood AC and Wilson JA. Stopping selegiline may lead to problems for patients. Lancet 1996;312: 702-3. 